\title{
Pharmacological and Phytochemical Screenings of Ethanol Extract of Etlingera linguiformis (Roxb.) R.M.Sm. Growing in Bangladesh
}

\author{
Md. Arafat Hossan', Mohammed Ibrahim¹, Md. Qamrul Ahsan ${ }^{1}$, Fahima Aktar ${ }^{2}$, Md. Ruhul \\ Kuddus $^{2}$, M. Mohi Uddin Chowdhury ${ }^{1}$ and Mohammad A. Rashid ${ }^{2}$ \\ ${ }^{1}$ Department of Pharmacy, Southern University Bangladesh, Chittagong, Bangladesh. \\ ${ }^{2}$ Department of Pharmaceutical Chemistry, Faculty of Pharmacy, University of Dhaka, Dhaka- 1000, Bangladesh.
}

\begin{abstract}
The present study was conducted to investigate the bio-activities of ethanol extract of Etlingera linguiformis (Roxb.) R.M.Sm. as well as to determine the chemical profiles of the extract. The antibacterial and antifungal activities of the crude extract were evaluated by the disc diffusion method against 4 Gram positive and 7 Gram negative pathogenic bacteria and 7 fungi using Ciprofloxacin and Fluconazole as standards, respectively. The minimum inhibitory concentration (MIC) was determined by the serial dilution method. The anti-atherothrombosis activity was assessed by using Streptokinase (SK) as standard. Moreover, the in-vitro anti-inflammatory and membrane stablization tests were performed. In the anti-bacterial and antifungal activity test, the zones of inhibition were found within the range of 10.0-15.0 and 10.0-22.0 mm, respectively. The highest zone of inhibition was obtained against Bacillus cereus $(15.0 \mathrm{~mm})$ and Blastomyces dermatitidis $(22.0 \mathrm{~mm})$. In the minimum inhibitory concentration (MIC) test the crude extract inhibited the growth of Blastomyces dermatitidis significantly at 31.2 $\mu \mathrm{g} / \mathrm{ml}$. In the anti-atherothrombosis activity test, the extract revealed moderate clot lysis by $15.15 \%$. Moreover, the extract produced inhibition of protein denaturation and haemolysis by $34 \%$ and $38.98 \%$ in the in vitro antiinflammatory and membrane stablization tests. Preliminary phytochemical screenings of the crude extractives demonstrated the presence of alkaloids, steroids, tannins, reducing sugars and gums. The extract also exhibited good biological activities. Therefore, the plant should be subjected to systematic bioactivity guided isolation in order to obtain the active molecules.
\end{abstract}

Key words: Etlingera linguiformis, Antimicrobial, Minimum Inhibitory Concentration, Anti-atherothrombosis, Anti-inflammatory, Membrane Stablization.

\section{Introduction}

The plants which naturally synthesize and accumulate some secondary metabolites, like alkaloids, glycosides, tannins, volatile oils and contain minerals and vitamins possess medicinal properties (De Smet, 1997). In the past, peoples of ancient civilizations depended greatly on local flora and fauna for their survival (Dossey, 2010). Ethnomedicine is a sub-field of ethnobotany or medical anthropology that deals with the study of traditional medicines: not only have those that have relevant written sources but especially those, whose knowledge and practices been orally transmitted over the centuries (Acharya et al., 2008). Etlingera linguiformis (Roxb.) R.M.Sm. (Family: Zingiberaceae, Bengali name: Tera) is a tall, leafy, perennial herb, upto $2 \mathrm{~m}$ high, has 30-45 cm long, oblong, lanceolate, glabrous leaves, with stout, copiously stoloniferous aromatic rhizome. In Bangladesh the plant grows in Chittagong Hill Tracts, Moulvi Bazar and in India it is available in Darjeeling. This plant is used as a medicinal plant in Bangladesh and pieces of rhizomes are chewed with betel leaf to cure sore throat in Hathazari area of Chittagong (Website-1, 2). Young leaves and shoots are used as leafy vegetables. Rhizomes are used as medicine to cure jaundice (Ramana et al., 2012). The rhizomes are strongly aromatic which contain about $0.4 \%$ essential oil with a fennel like smell, composed of about 19 components, such as methyl chevicol, methyl eugenol, $\beta$-pinene, asarone, eucalyptol and $\alpha$-pinene. The fresh leaves contain $0.15 \%$ essential oils, composed of about 39 components; a few are eucalyptol, $\beta$-pinene, $\alpha$-pinene, linalool, $\beta$-elemene, $\alpha$-selinene, $\beta$-terpinyl acetate, $\alpha$ phellandrene and juniper camphor (Website-3).

As part of our ongoing research with medicinal plant of Bangladesh (Kuddus et al., 2012; Amin et al.,2012) the

Correspondence to: Mohammad A. Rashid; E-mail: rashidma@du.ac.bd; rashidma@univdhaka.edu 
present study has been undertaken to evaluate the antimicrobial, anti-inflammatory, membrane stabilization and anti-atherothrombosis activities of the species to find out evidence for its folk uses and to introduce $E$. linguiformis grown in Bangladesh as a source of new drug candidate.

\section{Materials and Methods}

Collection and identification: The aerial parts of $E$. linguiformis (Roxb.) was collected from Chittagong Botanical Garden, Shitakando, Chittagong, Bangladesh in the November, 2011. The plant was identified by the experts of Bangladesh Forest Research Institute Herbarium, Chittagong where voucher specimen has been deposited.

Drying and grinding: After collection, the plant was separated from other plant parts and dust and then washed with running tap water. The plant was then subjected for shade dry at temperature not exceeding $50{ }^{\circ} \mathrm{C}$. The dry materials were grounded into a coarse powder with the help of a grinder and stored in airtight container and in a cool and dark until extraction commenced.

Hot extraction by Soxhlet extractor: Exactly $130 \mathrm{gm}$ of powder was extracted with $750 \mathrm{ml}$ of ethanol (99.98\%) in a Soxhlet apparatus (Quickfit, England) (Bhal and Bhal 1992). The extract was concentrated with a rotary evaporator (Heidolph, Germany) under reduced temperature and pressure to provide a gummy residue (15.49 gm, yield 11.92\%).

Preliminary phytochemical investigation: For preliminary phytochemical investigation the crude extract was subjected to various tests (Table 1) to determine the chemical nature of the extractive (Ali, 1993).

Screening for antimicrobial activity: The antibacterial and antifungal activities of the crude extract was evaluated by the disc diffusion method against 4 Gram positive and 7 Gram negative pathogenic bacteria and 7 fungi (Table 2) using Ciprofloxacin and Fluconazole as standards, respectively (Bauer et al., 1951). The organisms were collected from the Microbiology Lab., Department of Pharmacy, BGC Trust University, Chittagong, Bangladesh. The test organisms were maintained on nutrient agar slopes and were sub-cultured at regular intervals. These microorganisms served as test pathogens for antibacterial sensitivity test. The antimicrobial activity of test agent was determined by measuring the diameter of zone of inhibition expressed in $\mathrm{mm}$. The experiments were carried out in triplicate and the results have been shown as mean $\pm \mathrm{SEM}$.

Minimum inhibitory concentration (MIC): The minimum inhibitory concentration (MIC) of ethanol extract of E. linguiformis was determined (Table 2) by the serial tube dilution technique (Turnidge et al., 2003) in broth medium, containing graded concentration of the plant extract inoculated with the organisms.

Anti-inflammatory activity: To determine the antiinflammation activity (Tables 3 ) of the ethanol extract of E. linguiformis, 12 clean centrifuge tubes (three for positive control, acetyl salicylic acid, three for negative control, $99.8 \%$ ethanol and six for crude extract) were used. $1.0 \mathrm{ml}$ of $5 \%$ egg albumin solution was kept into all test tubes. Then $1 \mathrm{ml}$ of acetyl salicylic acid $(0.1 \mathrm{mg}), 1 \mathrm{ml}$ of ethanol and $1 \mathrm{ml}$ of ethanol extract $(1000 \mathrm{mg} / \mathrm{kg})$ added to the positive and negative and test groups marked test tubes, respectively. The $\mathrm{pH}(5.6 \pm 0.2)$ of all the reaction mixtures was adjusted by $1 \mathrm{~N} \mathrm{HCl}$. These were heated, cooled and after filtration, the absorbance was measured spectrophotometrically at $660 \mathrm{~nm}$ (Olajide et al., 2004).

Membrane stabilization activity: For this study, three clean centrifuge tubes were taken for positive control (acetyl salicylic acid), three for negative control (99.8\% ethanol) and six for crude ethanol extract and $1.0 \mathrm{ml}$ of $10 \%$ RBC suspension was added to each tube. Then 1.0 $\mathrm{ml}$ ethanol and $1.0 \mathrm{ml}$ acetyl salicylic acid were added to the negative control and positive control tubes respectively. On the other hand, for the test group, $1.0 \mathrm{ml}$ of ethanol extract $(1000 \mathrm{mg} / \mathrm{kg})$ was mixed. The $\mathrm{pH}$ $(7.4 \pm 0.2)$ of the reaction mixtures was adjusted by phosphate buffer. The tubes were then incubated in water bath and after cooling these were centrifuged at $2500 \mathrm{rpm}$ for 5 minutes. After filtration the absorbance of the supernatants were taken at $556 \mathrm{~nm}$. The total inhibition of haemolysis was then calculated (Table 4) by determining the \% inhibition of haemolysis (Shinde et al., 1999).

Anti-atherothrombosis activity: An aliquot of $4.0 \mathrm{ml}$ venous blood from each of the 10 healthy volunteers was collected and distributed in three different pre-weighed sterile microcentrifuge tubes ( 1 for crude extract, 1 for streptokinase as standard and 1 for ethanol as negative control). After clot formation the clot weight was 
determined by removing the serum without disturbing the clot. Then $100 \mu \mathrm{l}(5 \mu \mathrm{g} / \mu \mathrm{l})$ of ethanol extract, $100 \mu \mathrm{l}$ of streptokinase and $100 \mu 1$ of ethanol (99.8\%) were added to the microcentrifuge tubes marked as test, positive control and negative control respectively. After incubation at 37 ${ }^{\circ} \mathrm{C}$ for 90 minute, the percentage of clot lysis (Table 5) was calculated (Prasad et al., 2006).

\section{Results and Discussion}

Preliminary phytochemical screening: The crude extractive when tested with various chemical reagents demonstrated the presence of alkaloids, steroids, tannins, reducing sugars and gums as shown in Table 1.

Pharmacological studies: In the disc diffusion antibacterial activity test, the zones of inhibition was found within the range of 10.0-15.0 mm. The highest zone of inhibition $(15.0 \mathrm{~mm})$ was obtained against B. cereus, followed by 13.0, 12.0, 11.0, 11.0, 11.0 and $10.0 \mathrm{~mm}$ against $S$. aureus, $P$. aeruginosa, $B$. subtilis, $B$. megateriuum, $S$. Paratyphi and Shigella sonnei, respectively. The crude extract strongly inhibited the growth of $B$. cereus and $P$. aeruginosa when compared with standard ciprofloxacin. But the tested extract produced no inhibition to the E. coli, S. dysenteriae, S. Typhi and V. cholera (Table 2).

During the minimum inhibitory concentration (MIC) determination, the crude extract inhibited the growth of Blastomyces dermatitidis significantly at the dose of 31.2 $\mu \mathrm{g} / \mathrm{ml}$ followed by Bacillus cereus and Micrococcus $(62.50 \mu \mathrm{g} / \mathrm{ml})$, S. aureus, A. niger, and C. albicans by $125.0 \mu \mathrm{g} / \mathrm{ml}$ and Bacillus subtilis, B. megateriuum, $P$. aeruginosa, S. Paratyphi and $P$. ovale by $250.0 \mu \mathrm{g} / \mathrm{ml}$ (Table 2).

Table 1. Chemical groups present in the extract of Etlingera linguiformis.

\begin{tabular}{llc}
\hline \multicolumn{1}{c}{ Test for } & \multicolumn{1}{c}{ Test performed } & $\begin{array}{c}\text { EtOH Extract of } \\
\text { E. linguiformis }\end{array}$ \\
\hline Alkaloids & Meyer's test & + \\
& Dragendorff's test & + \\
& Wagner's test & - \\
& Hager's test & - \\
& Tannic acid test & + \\
Glycosides & Salkowski test & + \\
& Libermann-Burchared test & + \\
Steroids & Salkowski test & + \\
Tannins & Libermann-Burchared test & + \\
Flavonoids & Ferric chlorides test & - \\
Saponins & Potassium dichromate test & - \\
Reducing sugars & Conc. HCl and alcoholic test & + \\
Gums & Shake test (aq. solution) & + \\
\hline
\end{tabular}

$(+)=$ present; $(-)=$ absent

In the present study for in-vitro anti-inflammatory test, the crude ethanol extract of E. linguiformis (1000 $\mathrm{mg} / \mathrm{kg}$ ) showed mean inhibition of protein denaturation $34 \pm 0.002$ whereas, for ASA it was found to be $52 \pm 0.0007$ (Table 3). The ability of ethanol extract of E. linguiformis to inhibit thermal and hypotonic solution-induced protein denaturation was found to be mild.
The test extract $(1000 \mathrm{mg} / \mathrm{kg})$ inhibited the heat induced haemolysis of RBCs by $38.98 \pm 0.00736$ whereas, the standard aspirin showed $89.83 \pm 0.002041$ (Table 4). The stabilization activity for the crude extract of $E$. linguiformis was found to be reasonable. Although the precise mechanism of this membrane stabilization is yet to be elucidated, it is thought that the ethanol extract of the plant may possibly inhibit the release of lysosomal 
Table 2. Antibacterial activity of Etlingera linguiformis at $500 \mu \mathrm{g} / \mathrm{disc}$ and standard.

\begin{tabular}{|c|c|c|c|}
\hline \multirow[b]{2}{*}{ Test organisms } & \multicolumn{2}{|c|}{ Diameter of zone of inhibition $(\mathrm{mm})$} & \multirow[b]{2}{*}{$\operatorname{MICs}(\mu \mathrm{g} / \mathrm{ml})$} \\
\hline & $\begin{array}{l}\text { EtOH Extract } \\
(500 \mu \mathrm{g} / \text { disc })\end{array}$ & $\begin{array}{c}\text { Standard } \\
(30 \mu \mathrm{g} / \mathrm{disc})\end{array}$ & \\
\hline Gram positive bacteria & \multicolumn{3}{|c|}{ Ciprofloxacin } \\
\hline Bacillus cereus & $15.0 \pm 2.00^{\mathrm{c}}$ & $13.0 \pm 1.26$ & 62.5 \\
\hline B. megateriuum & $11.0 \pm 1.00^{\mathrm{c}}$ & $12.0 \pm 0.58$ & 250.0 \\
\hline B. subtilis & $11.0 \pm 2.00^{\mathrm{c}}$ & $15.0 \pm 1.04$ & 250.0 \\
\hline Staphylococcus aureus & $13.0 \pm 0.00^{\mathrm{c}}$ & $14.0 \pm 0.76$ & 125.0 \\
\hline \multicolumn{4}{|l|}{ Gram negative bacteria } \\
\hline Escherichia coli & nd & $15.0 \pm 0.50$ & nd \\
\hline Pseudomonas aeruginosa & $12.0 \pm 1.00^{\mathrm{d}}$ & $11.0 \pm 1.04$ & 250.0 \\
\hline Salmonella Typhi & nd & $12.0 \pm 0.50$ & nd \\
\hline Salmonella Paratyphi & $11.0 \pm 1.00^{\mathrm{c}}$ & $12.0 \pm 1.50$ & 250.0 \\
\hline Shigella dysenteriae & nd & $15.0 \pm 0.58$ & nd \\
\hline Sh. sonnei & $10.0 \pm 1.00^{\mathrm{a}}$ & $14.0 \pm 0.29$ & nd \\
\hline Vibrio cholerae & nd & $14.0 \pm 0.29$ & nd \\
\hline Fungi & \multicolumn{3}{|c|}{ Fluconazole } \\
\hline Aspergillus niger & $14.0 \pm 2.65^{\mathrm{d}}$ & $14.0 \pm 0.76$ & 125.0 \\
\hline Blastomyces dermatitidis & $22.0 \pm 3.00^{\mathrm{a}}$ & $12.0 \pm 0.76$ & 31.5 \\
\hline Candida albicans & $15.0 \pm 2.65^{\mathrm{c}}$ & $13.0 \pm 0.50$ & 125.0 \\
\hline Cryptococcus neoformans & $10.0 \pm 1.00^{\mathrm{c}}$ & $12.0 \pm 1.50$ & nd \\
\hline Microsporum sp. & $20.0 \pm 2.65^{\mathrm{b}}$ & $11.0 \pm 1.32$ & 62.5 \\
\hline Pityrosporum ovale & $11.0 \pm 1.00^{\mathrm{c}}$ & $13.0 \pm 1.26$ & 250.0 \\
\hline Trichophyton sp. & $14.0 \pm 1.00^{\mathrm{d}}$ & $14.0 \pm 0.50$ & 125.0 \\
\hline
\end{tabular}

${ }^{\mathrm{a}} \mathrm{p}<0.02,{ }^{\mathrm{b}} \mathrm{p}<0.05,{ }^{\mathrm{c}} \mathrm{p}<0.10,{ }^{\mathrm{d}} \mathrm{p}<0.50$; MICs: Minimum inhibitory concentrations nd: Not detected; The diameter of zone of inhibition is expressed as mean \pm SEM $(n=3)$; SEM: standard error of mean; Zone of inhibition under $8 \mathrm{~mm}$ was considered as less active and was discarded.

content of neutrophils at the site of inflammation. That provides evidence for poor membrane stabilization as an additional mechanism of their anti-inflammatory effect.

Table 3. In-vitro anti-inflammatory activity of ethanol extract of E. linguiformis.

\begin{tabular}{lccc}
\hline Test groups & SD & SEM & $\begin{array}{c}\text { Inhibition of protein } \\
\text { denaturation }\end{array}$ \\
\hline $\begin{array}{l}\text { Control } \\
\text { (Ethanol) }\end{array}$ & 0.0005 & 0.0004 & $0.00 \pm 0.00108$ \\
$\begin{array}{l}\text { Positive control } \\
\text { (ASA 0.1 mg) }\end{array}$ & 0.001 & 0.0007 & $52 \pm 0.0007^{\mathrm{b}}$ \\
$\begin{array}{l}\text { EEEL (1000 } \\
\mathrm{mg} / \mathrm{kg} \text { ) }\end{array}$ & 0.0005 & 0.0004 & $34 \pm 0.002^{\mathrm{a}}$ \\
\hline
\end{tabular}

*SEM $=$ Standard error of mean, Total inhibition of protein denaturation $=\%$ MIPD \pm SEM, ${ }^{a} \mathrm{p}<0.02,{ }^{\mathrm{b}} \mathrm{p}<0.001 ;$ EEEL $=$ Ethanol Extract of E. linguiformis; ASA = Acetyl salicylic acid

In the study for anti-atherothrombosis activity test, addition of $100 \mu \mathrm{SK}$, a positive control (30,000 I.U.) to the clots along with $90 \mathrm{~min}$ of incubation at $37^{\circ} \mathrm{C}$, showed $81.53 \%$ clot lysis. On the other hand, clots when treated with $100 \mu \mathrm{l}$ ethanol (negative control) showed only negligible clot lysis $(2.49 \%)$. After treatment of clots with $100 \mu \mathrm{l}$ of $E$. lingueformis clot lysis $15.15 \%$ was obtained. Statistical representation of the effective clot lysis percentage, by the crude extract, positive thrombolytic control (streptokinase) and negative control (ethanol) is tabulated in Table 5 .

Table 4. Tabulation for in-vitro membrane stabilization test of ethanol extract of $E$. linguiformis.

\begin{tabular}{lccc}
\hline \multicolumn{1}{c}{ Test groups } & SD & SEM & $\begin{array}{c}\text { Total inhibition of } \\
\text { haemolysis }\end{array}$ \\
\hline Control (Ethanol) & 0.010408 & 0.00736 & $00.00 \pm 0.00736$ \\
$\begin{array}{l}\text { Positive control } \\
\text { (ASA 0.1 mg) }\end{array}$ & 0.002887 & 0.002041 & $89.83 \pm 0.002041^{\mathrm{a}}$ \\
EEEL (1000mg/kg) & 0.010408 & 0.00736 & $38.98 \pm 0.00736^{\mathrm{b}}$ \\
\hline
\end{tabular}

*Total inhibition of haemolysis $=\%$ IMHLs \pm SEM, ${ }^{a} p<0.01$, ${ }^{b} \mathrm{p}<0.05$ 
Table 5. Result of anti- atherothrombosis activity of ethanol extract of $E$. linguiformis.

\begin{tabular}{lc}
\hline \multicolumn{1}{c}{ Controls/extract } & Clot lysis (\%) \\
\hline Ethanol (negative control) & $2.49 \pm 0.39$ \\
Streptokinase (positive control) & $81.53 \pm 3.7049$ \\
EEEL & $15.15 \pm 2.432$ \\
\hline
\end{tabular}

Values are expressed as mean \pm SEM (standard error of mean)

\section{Conclusion}

The present research was conducted to investigate the preliminary biological activities of ethanol extract of $E$. linguiformis (Roxb.) R.M.Sm. as well as to determine the phytochemical profiles of the extract. Preliminary phytochemical screenings with the crude extractives demonstrated the presence of alkaloids, steroids, tannins, reducing sugars and gums. This plant showed moderate antimicrobial activity with low MIC against several microorganisms. The ability of ethanol extract of this plant to inhibit thermal- and hypotonic solution- induced protein denaturation was found to be mildly significant and provides evidence for poor membrane stabilization as an additional mechanism of their anti-inflammatory effect. So, the results obtained from this study indicate that this plant species could be useful in the search for new natural bioactive compounds and thus warrant for further studies.

\section{Acknowledgements}

The authors wish to thank the authority of the department of Pharmacy, BGC Trust University, Chittagong, Bangladesh for supplying test organisms to perform these investigations.

\section{References}

Acharya, D. and Shrivastava, A. 2008. Indigenous herbal medicines: Tribal formulations and traditional herbal practices. Aavishkar Publishers Distributor, Jaipur/India, p. 440.

Ali, M. 1993. Text Book of Pharmacognosy, CBS Publishers and Distributors, New Delhi-110002, N. Ed., 2009, pp. 96-97, $140,283$.
Amin, M.A., Chowdhury, I.A., Mahbub, K.M.M., Sattar, S., Shahriar, M., Kuddus, M.R. and Rashid, M.A. 2012. Antiinflammatory and analgesic activities of Asteracantha longifolia Nees. Bangladesh Pharm. J. 15, 171-176.

Bauer, A.W., Kibry, W.M.M., Sheries, J.C. and Turek, M. 1951. Antibiotic succeptibility testing by a standard single disc method. Am. J. Sci .1, 103, 195.

Bhal, B.S. and Bhal, A. 1992. A Text Book of Organic Chemistry, $13^{\text {th }}$ ed. S. Chand \& Company Ltd., pp. 5-6, 11112, 14.

De Smet, P.A. 1997. The role of plant derived drugs and herbal medicines in healthcare. Drugs. 54,108.

Dossey, A. 2010. Insects and their chemical weaponry: New potential for drug discovery. Nat. Prod. Rep. 27, 17371757.

Kuddus, M.R., Alam, M.S., Chowdhury, S.R., Rumi, F., Sikder, M.A. and Rashid, M.A. 2012. Evaluation of membrane stabilizing activity, total phenolic content, brine shrimp lethality bioassay, thrombolytic and antimicrobial activities of Tagetes patula L. J. Pharmacogn. Phytochem. 1, 57-63.

Olajide, O.A., Echianu, C.A., Adedapo, A.D. and Makinde, J.M. 2004. Anti-inflammatory studies on Adenanthera pavonina seed extract. Inflammopharmacology. 12, 196-202.

Prasad, S., Kashyap, R.S., Deopujari, J.Y., Purohit, H.J., Taori, G.M. and Daginawala, H.F. 2006. Development of an invitro model to study clot lysis activity of thrombolytic drugs. Thrombosis J. 4, 14

Ramana, M.V., Tagore, J.K. and Bhattacharjee, A. 2012. Report of two medicinal and aromatic gingers from Andaman and Nicobar Islands, India. J. Threatened Taxa. 4, 2582-2586.

Shinde, U.A., Phadke A.S., Nair A.M., Mungantiwar A.A., Dikshit V.J. and Saraf M.N. 1999. Membrane stabilizing activity- a possible mechanism of action for the antiinflammatory activity of Cedrus deodara wood oil. Fitoterapia 70, 251-257.

Turnidge, J.D., Ferraro, M.J. and Jorgensen, J.H. 2003. Manual of Clinical Microbiology. 8th Ed. Washington. Am. Soc. Clin. Microbiol. p. 1103.

Website-1: http://www.mpbd.info/plants/etlingera-linguiformis. php

Website-2: http://portal.nbc.gov.bt/portalBhutan/speciesRecord/ 3919

Website-3: http://www.mpbd.info/plants/etlingera-linguiformis. php $>$. Online version dated 23 September 2011. 